\title{
Effectiveness of silicon-containing additives in poultry feeding
}

\author{
Lyudmila Andreyenko ${ }^{1}$, Sergey Nikolaev ${ }^{1, *}$, Angela Karapetyan $^{1}$, Elena Vorontsova $^{1,2^{*}}$, and Elena Kornilova ${ }^{1}$ \\ ${ }^{1}$ Volgograd State Agrarian University, 400002 Volgograd, Russia \\ ${ }^{2}$ Volga region research institute of manufacture and processing of meat-and-milk production, 400131 Volgograd, Russia
}

\begin{abstract}
The scientists of the Volgograd State Agrarian University and Samara State Agrarian University carried out research on the use of bio-soluble silicon form as a part of the «NaBiKat» additive in various concentrations in the rations of pullets and egg-laying hens in conditions of the Volgograd region at the facilities of Volzhskaya Poultry Farm CJSC in 2015- 2019. For the experiment, the birds were selected by the method of similar groups (control and three experimental). The control group poultry received a standard ration; the additive was additionally added to the feed of experimental groups 1,2 and 3 in a concentration of $0.12 \%, 0.15 \%$ and $0.17 \%$, respectively, depending on the fodder weight. The digestibility of dry matter in the body of young and adult laying hens was higher in the experimental groups compared to the control, by $1.82 \%$ and $1.79 \%, 3.13 \%$ and $3.08 \%, 1.97 \%$ and 1.93 , respectively. The use of the silicon-containing polyadditive "NaBiKat" in various dosages contributed to the increase in pullets' live weight by the end of the experiment by $4.15-4.35 \%$, and to egg productivity of hens - by $0.56 \%-1.37 \%$. At the same time, there was a decrease in costs for a dozen eggs and $1 \mathrm{~kg}$ of egg mass.
\end{abstract}

\section{Introduction}

Nowadays, in the agricultural sector, a purposeful search for biologically active substances that promote selfoptimization of metabolism [1-4], increase in zootechnical indicators, productivity and economic feasibility of the industry is becoming increasingly important $[5,6]$. The results of recent biochemical studies indicate a significant expansion of the list of chemical elements, the entry of which into the animals' organism requires strict accounting and control of the fodder nutritional value for them $[7,8]$.

We are talking mainly about ultramicroelements, whose biological functions are confirmed by modern scientific methods and methods of biochemical analysis. Silicon plays the main role in such developments [9].

Silicon provides the laying hens' physiologically normal viability throughout the entire growing period, participates in the metabolism of phosphorus, in lipid metabolism, promotes collagen biosynthesis, and calcium accumulation in bone tissues [10].

It is important to note that the poultry ration enrichment in silicon through the use of natural feeds is impossible, since the natural silicon compounds in plants are in a low bioavailable form for digestion in the poultry's body [8].

Thanks to the development of special organosilicon additives and their testing in the feeding of egg-laying poultry, Russian scientists managed to create a siliconcontaining polyadditive "NaBiKat", which is a low- flowing grey powder with a specific smell [7]. The composition of this nanobiological feed additive includes rice germ layers and green tea gallo catechins in chelate form, four dozens of microelements in bioavailable forms, including bio-soluble and organically bound form of silicon [11].

This additive was developed by the Institute of Solid State Chemistry and Mechanochemistry of the Siberian Branch of the Russian Academy of Sciences (O.I. Lomovsky, E.V. Shapolova) and LLC "Center for the Implementation of Technologies", Novosibirsk, according to TS 9296-001-60284021-2010 by the method of non-chemical synthesis in the solid-phase process fermentation without a preliminary stage of dissolution from natural raw materials - plant origin gallocatechins and a water-soluble monomolecular form of silicon (chelates), isolated from plant sources [5, 7].

The purpose of our complex research was to study the influence of fodder supplement "NaBiKat" in the composition of mixed feeds on digestibility and nutrient use of experimental pullets and egg-laying hens.

\section{Material and research methods}

The young and adult egg-laying hens were studied from 2015 to 2019 in the conditions of CJSC Volzhskaya Poultry Farm in the Sredneakhtubinsky district of the Volgograd region. Compound feed for the control and experimental groups of poultry was manufactured under the conditions of this enterprise.

The general design of research is presented in Fig. 1.

\footnotetext{
Corresponding author: fsd_58@mail.ru
} 
Effectiveness of silicon-containing supplements use in poultry feeding in the conditions of Lower Volga region

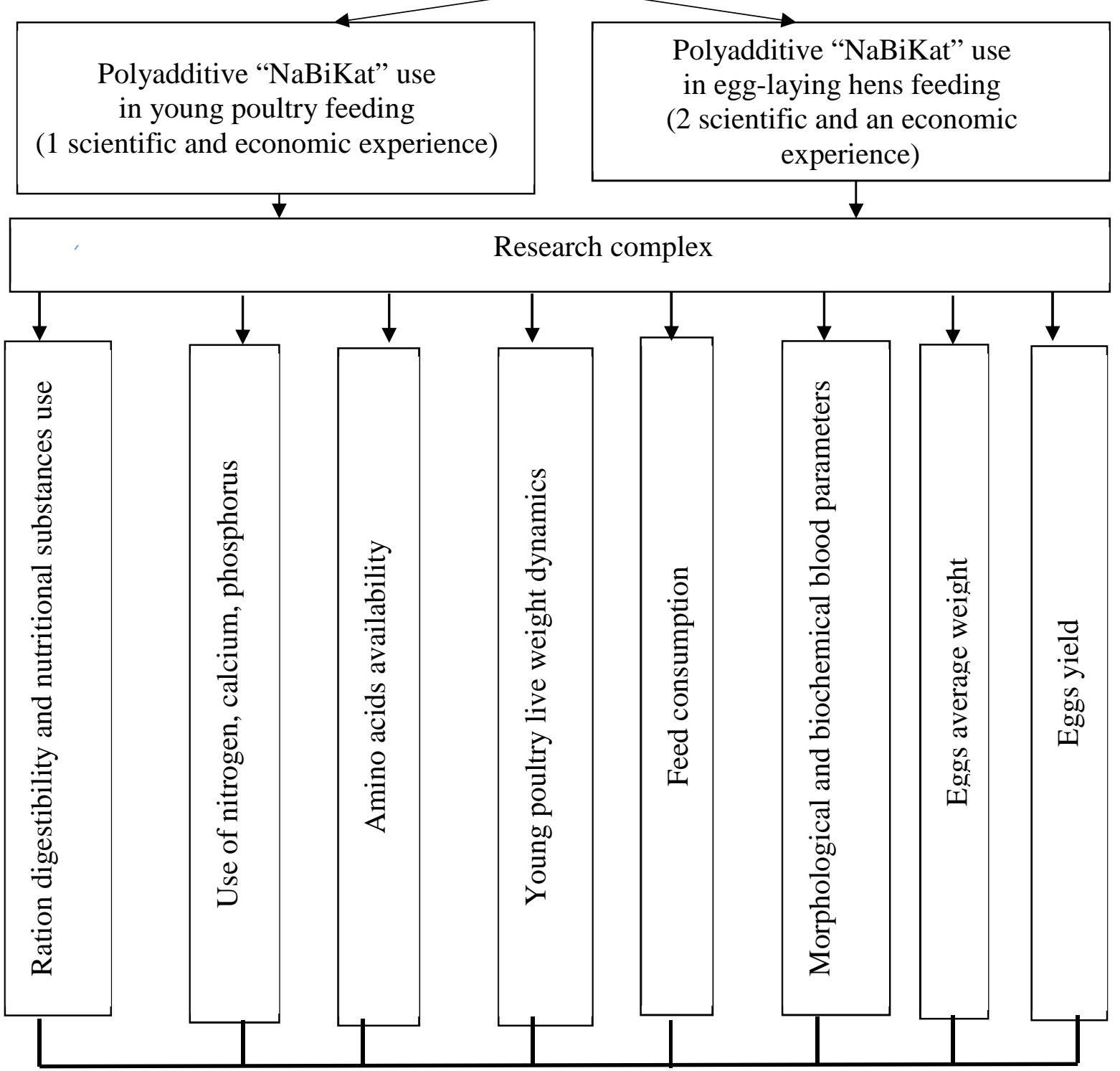

Fig. 1. General research scheme

To determine the compound feeds digestibility in the young and egg-laying hens body, a balance experiment was carried out, during which the basic ration nutrients digestibility coefficients were calculated on the basis of the feed samples chemical composition, poultry manure and feces. For this purpose, three heads were selected from each group of birds and placed in special coops.

The dynamics of body weight was determined by weighing the birds from the control coop in the accounting period.

All obtained data were processed biometrically according to the N.A. Plokhinsky method using Microsoft Excel package. The reliability of the differences was checked with the Student's criterion, with three thresholds of reliability $(* \mathrm{P}>0.95, * * \mathrm{P}>0.99, * * * \mathrm{P}>0.999)$.

\section{Research results}

The first scientific and economic experiment considering the use of polyadditive "NaBiKat" with mixed fodder was carried out on young hens. Four groups of birds 100 heads each were formed by using the method of analogues. A balanced mixed fodder used at the poultry farm was fed to the control group of young poultry, and pullets from the experimental groups 1,2 and 3 were fed the same diet with addition of "NaBiKat" at doses of $0.12 \%, 0.15 \%$ and $0.17 \%$ by weight of the mixed fodder, respectively.

Research results reflecting the experimental chicken nutrient digestibility coefficients are given in Table 1. 
Table 1. Diet nutrient digestibility coefficients and nitrogen utilization by experimental pullets, $\%(\mathrm{M} \pm \mathrm{m})$

\begin{tabular}{|l|c|c|c|c|}
\hline \multirow{2}{*}{ Digestibility coefficient } & \multicolumn{5}{c|}{ Group } \\
\cline { 2 - 5 } & Control & Experimental 1 & Experimental 2 & Experimental 3 \\
\hline Dry matter & $71.67 \pm 4.12$ & $73.49 \pm 4.39$ & $74.80 \pm 3.71$ & $73.64 \pm 4.40$ \\
\hline Organic matter & $74.53 \pm 4.47$ & $76.42 \pm 2.74$ & $77.79 \pm 1.58$ & $76.58 \pm 2.75$ \\
\hline Crude protein & $88.79 \pm 3.54$ & $90.21 \pm 4.22$ & $90.93 \pm 2.65$ & $90.39 \pm 4.23$ \\
\hline Crude fiber & $19.38 \pm 0.96$ & $20.02 \pm 1.11$ & $20.26 \pm 1.40$ & $20.06 \pm 1.12$ \\
\hline Raw fat & $96.11 \pm 3.65$ & $97.03 \pm 2.18$ & $97.85 \pm 4.02$ & $97.22 \pm 2.18$ \\
\hline Nitrogen use & 63.03 & 63.69 & 64.32 & 63.90 \\
\hline from accepted\% & 88.61 & 88.53 & 88.87 & 88.79 \\
\hline from digested,\%
\end{tabular}

The dry matter digestibility coefficient in the poultry control group was $71.67 \%$, in the experimental group it was $73.49 \%, 74.80 \%$ and $73.64 \%$, which is higher compared to the control by $1.82 \%, 3.13 \%$ and $1.97 \%$; the organic matter digestibility coefficient in the control group was $74.53 \%$, in the experimental groups it was $76.42 \%, 77.79 \%$ and $76.58 \%$, which is higher compared to the control by $1.82 \%, 3.26 \%$ and $2.05 \%$; crude protein digestibility coefficient in the control group was $88.79 \%$, in the experimental groups it was $90.21 \%, 90.93 \%$ and $90.39 \%$, which is higher compared to the control by $1.42 \%$ and $2.14 \%$ and $1.60 \%$; raw fiber digestibility coefficient in the control group was $19.38 \%$, in the experimental groups it was $20.02 \%, 20.26 \%$ and $20.06 \%$, which is higher compared to the control by $0.64 \%, 0.88 \%$ and $0.68 \%$; raw fat digestibility coefficient in the control group was $96.11 \%$, in the experimental groups it was $97.03 \%, 97.85 \%$ and $97.22 \%$, which is higher compared to the control by $0.92 \%, 1.74 \%$ and $1.11 \%$ respectively. The difference is not significant.

In order to determine the degree of metabolic processes, a balance experiment was carried out to determine the amount of nitrogen utilization.

Polyadditive "NaBiKat", introduced into the diet of poultry experimental groups, contributed to the change in the nitrogen use in the chickens' body. Thus, the nitrogen use in the control group was $63.03 \%$, in experimental groups it was $63.69 \%, 64.32 \%$ and $63.90 \%$, respectively, which is higher than in the control one by $0.66 \%, 1.29 \%$ and $0.87 \%$ respectively. This difference is not reliable.

The survivability of the birds in the control and experimental groups was $100 \%$.

Controlling the chickens' growth is an important step in the edible eggs production technology and largely determines its effectiveness.
According to the results of experimental chickens weighing by the 120-day age in the control group, the live weight was $1469 \mathrm{~g}$. In the 1-, 2- and 3-poultry groups, the live weight reached 1530, 1571 and $1533 \mathrm{~g}$, which exceeds the control indicators by $61 \mathrm{~g}(4.15 \%), 102 \mathrm{~g}$ $(6.94 \%)$ and $64 \mathrm{~g}(4.35 \%)$, respectively, with $100 \%$ livestock safety.

The poultry control group average daily increase at the end of the period was $11.63 \mathrm{~g}$, and in the experimental groups, respectively, higher by $1.03 \mathrm{~g}(8.86 \%), 1.3 \mathrm{~g}$ $(11.18 \%)$ and $1.07 \mathrm{~g}(9.20 \%)$. This indicates a high growth rate and increased metabolic processes with the introduction of the studied supplements into the rations.

Lower feed consumption per $1 \mathrm{~kg}$ increase in live weight was observed in the pullets of experimental groups, it was $4.03 \mathrm{~kg}, 3.90 \mathrm{~kg}$ and $4.04 \mathrm{~kg}$, respectively, by $0.21 \mathrm{~kg}(4.96 \%), 0.34 \mathrm{~kg}(8.02 \%)$ and $0.20 \mathrm{~kg}(4.72 \%)$ less in comparison with the control one. Thus, the introduction of polyadditive "NaBiKat" into the mixed fodder composition for young poultry contributed to a better digestion and nutrient absorption, which affected growth rates, live weight and average daily gains.

The second scientific and economic experiment was carried out on egg-laying hens. The birds were assigned to groups according to the method of analogues. The conditions of stock keeping, the front of feeding and watering, the microclimate parameters in all groups were the same and corresponded to the recommendations. Four groups were formed from the resulting bird (49 heads each). The control group of chickens got a standard diet. Birds of the experimental groups 1, 2 and 3 in addition to the basic diet got $0.12 \%, 0.15 \%$ and $0.17 \%$ by weight of the mixed fodder polyadditive "NaBiKat."

Research results for diet nutrient digestibility coefficients of experimental egg- laying hens are given in Table 2.

Table 2. Rations nutrient digestibility coefficient and nitrogen use by experimental egg-laying hens, $\%(\mathrm{M} \pm \mathrm{m})$

\begin{tabular}{|l|c|c|c|c|}
\hline \multirow{2}{*}{ Coefficient } & \multicolumn{4}{c|}{ Group } \\
\cline { 2 - 5 } & Control & Experimental 1 & Experimental 2 & Experimental 3 \\
\hline Dry matter & $70.26 \pm 4.24$ & $72.05 \pm 5.57$ & $73.34 \pm 2.86$ & $72.19 \pm 5.588$ \\
\hline Organic matter & $73.07 \pm 5.06$ & $74.92 \pm 3.90$ & $76.27 \pm 6.31$ & $75.07 \pm 3.91$ \\
\hline Crude protein & $87.04 \pm 4.90$ & $88.44 \pm 6.48$ & $89.14 \pm 3.86$ & $88.62 \pm 6.50$ \\
\hline Crude fiber & $19.0 \pm 2.07$ & $19.63 \pm 1.52$ & $19.85 \pm 1.36$ & $19.67 \pm 1.53$ \\
\hline Raw fat & $94.22 \pm 3.91$ & $95.12 \pm 4.90$ & $95.93 \pm 3.89$ & $95.31 \pm 4.91$ \\
\hline Nitrogen use from accepted, \% & $51.16 \pm 2.36$ & $52.09 \pm 2.81$ & $52.85 \pm 1.32$ & $52.43 \pm 2.82$ \\
\hline
\end{tabular}


The dry matter digestibility coefficient in the control group was $70.26 \%$, in the experimental group $1-72.05 \%$, which is higher than in the control group by $1.79 \%$, in the experimental group $2-73.34 \%$, which is higher than in control one by $3.08 \%$; in the experimental group 3 $72.19 \%$, which is higher than in the control one by $1.93 \%$; the organic matter digestibility coefficient in the control group was $73.07 \%$, in the experimental group 1 it was $74.92 \%$, which is higher than in the control one by $1.85 \%$, in the experimental group 2 it was $76.27 \%$, which is higher than in the control by $3.2 \%$, in the experimental group 3 it was $75.07 \%$, which is $2.0 \%$ higher than in the control; crude protein digestibility coefficient in the control group was $87.04 \%$, in the experimental group 1 it was $88.44 \%$, which is higher than in the control one by $1.34 \%$, in the experimental group 2 it was $89.14 \%$, which is higher than in the control one by $2.1 \%$, in the experimental group 3 it was $88.62 \%$, which is higher than in the control by $1.58 \%$; raw fiber digestibility coefficient in the control group was $19.0 \%$, in the experimental group 1 it was $19.63 \%$, which is higher than in the control one by $0.63 \%$, in the experimental group 2 it was $19.85 \%$, which is higher than in control one by $0.85 \%$, in the experimental group 3 it was $19.67 \%$, which is higher than the control by $0.67 \%$; raw fat digestibility coefficient in the control group was $94.22 \%$, in the experimental group 1 it was $95.12 \%$, which is higher than in the control one by $0.90 \%$, in the experimental group 2 it was $95.93 \%$, which is higher than in the control one by $1.71 \%$, in the experimental group 3 it was $95.31 \%$, which is higher than in the control by $1.09 \%$. This difference is not significant.

Improvement of metabolic processes in the particular protein metabolism in the egg-laying hens' body fed with mixed fodder, in which the silicon-containing polyadditive "NaBiKat" was added, contributed to the increase in the nitrogen use. The highest nitrogen use from the accepted was in the experimental group 2 (with the concentration of silicon-containing polyadditive "NaBiKat" of $0.15 \%$ ) and amounted to $52.85 \%$, which is higher than in the control one by $1.69 \%$, in experimental group $1-52.09 \%$ which is higher than in the control one by $0.93 \%$, in the experimental group $3-52.43 \%$ which is higher than in the control group by $1.27 \%$.

The egg production of experimental chickens is given in Table 3.

Table 3. Laying hens egg productivity

\begin{tabular}{|l|c|c|c|c|}
\hline \multirow{2}{*}{\multicolumn{1}{c|}{ Indicator }} & \multicolumn{4}{c|}{ Group } \\
\cline { 2 - 5 } & Control & Experimental & Experimental & Experimental \\
& & 1 & 2 & 49 \\
\hline & 49 & 15807 & 15964 & 15959 \\
\hline Average number of chickens, heads & 15744 & 322.6 & 325.8 & 325.7 \\
\hline Received eggs total, pieces & 321.30 & 88.38 & 89.26 & 89.23 \\
\hline on average egg-layer & 88.03 & 63.60 & 64.33 & 63.98 \\
\hline \% of egg-laying & 63.17 & 1005.33 & 1021.38 & 1026.64 \\
\hline Average weight of eggs, g & 994.55 & 2041.68 & 2028.70 & 2034.92 \\
\hline Received egg mass, kg & 2076.23 & 2.03 & 1.97 & 1.98 \\
\hline Feed consumption, kg: total & 2.09 & 1.29 & 1.27 & 1.27 \\
\hline per1 kg of egg mass & 1.32 & & & \\
\hline per 10 eggs & & & & 49 \\
\hline
\end{tabular}

The results of scientific and business experiments showed that the average egg productivity per hen for the experience period in the experimental groups was 321.30 ; 322.6; 325.7 and 325.8 units, which exceeds the control by $0.56 \%, 1.65 \%$ and $1.37 \%$, respectively. The best results were achieved in the experimental group of birds with the introduction of the preparation "NaBiKat" in the concentration of $0.15 \%$ by weight of the mixed fodder.

In the experimental chicken groups, a high intensity of egg laying was observed, which was $88.38 \%, 89.26 \%$ and $89.23 \%$, which is $0.35 \%, 1.23 \%$ and $1.20 \%$ higher than the control group, respectively. The average egg weight of chickens in the experimental groups was higher than the control one, by $0.43 \%, 1.16 \%$ and $0.81 \%$, respectively. In the experimental groups of birds, the feed consumption per $1 \mathrm{~kg}$ of egg mass were less than the control by $0.06 \mathrm{~kg}, 0.12 \mathrm{~kg}$ and $0.11 \mathrm{~kg}$, respectively; when calculating per 10 eggs, the feed consumption in the experimental groups were less by $0.03 \mathrm{~kg}, 0.05 \mathrm{~kg}$ and $0.05 \mathrm{~kg}$, respectively, compared with the control one.
Thus, the use of mixed fodder with silicon-containing polyadditive "NaBiKat" for egg-laying hens led to an improvement in the compound feed nutrients digestion, the increase in egg production and a decrease in feed consumption per unit of production.

\section{Conclusion}

The scientific literature describes the functions of silicon in biological systems and the effect of its compounds on physiological processes. However, the issues of rationing silicon dosages, its effects on digestibility and nutrient utilization, the productive qualities of farm animals and poultry require further research.

Experience in assessing the effectiveness of the additive "NaBiKat" based on natural silicon-containing ingredients in the feed of young animals and egg-laying hens showed that its introduction into the main diet in doses from $0.12 \%$ to $0.17 \%$ by weight of the compound feed contributes to the nutrients digestibility and use by 
an experimental bird, provides the most intensive growth of pullets and egg productivity of egg-laying hens. The greatest positive dynamics was in the poultry of the experimental group 2, whose feed contained $0.15 \%$ of silicon-containing "NaBiKat". Thus, to improve the poultry production efficiency in the Volgograd region, it is advisable to use a silicon-containing polyadditive "NaBiKat" in the Haysex Brown egg cross poultry feeding.

\section{References}

1. G.V. Fedotova, I.F. Gorlov, A.V Glushchenko, M.I. Slozhenkina, A.K. Natyrov, Trends of scientific and technical development of agriculture in Russia (2020) doi: 10.1007/978-3-030-29586-8_23

2. I.F. Gorlov, Z.B. Komarova, D.N. Nozhnik, E.Y. Zlobina, E.V. Karpenko, Aspartate-complexed minerals in feeding broiler chickens, Research Journal of Pharmaceutical, Biological and Chemical Sciences, 7(5), 2890-2898 (2016)

3. I.F. Gorlov, M.I. Slozhenkina, Z.B. Komarova, V.V. Golovin, O.E. Krotova, S.M. Ivanov, A.V. Rudkovskaya et al., Mineral feed additive to prevent chickens' heat stress, International Journal of Pharmaceutical Research, 12(3), 168-173 (2020) doi: 10.31838/ijpr/2020.12.03.030

4. M.S. Mazanko, A.I. Klimenko, I.F. Gorlov, A.V. Usatov, Z.B. Komarova, N.I. Mosolova, M.A. Kolosova et al., Products of solid-phase probiotic bacilli fermentation increase food conversion efficiency and stimulate chicken growth, American Journal of Biochemistry and Biotechnology, 14(4), 262-271 (2018) doi: 10.3844/ajbbsp.2018.262.271

5. Ye.A. Lipova, A.K. Karapetyan, M.A. Sherstyugina, Application in feeding poultry BVMK, Proceedings of the Nizhnevolzhsky Agro-University Complex: Science and Higher Professional Education, 1 (2014)

6. S.N. Qaisrani, Dietary factors affecting hindgut protein fermentation in broilers: a review, World's Poultry Sci. J., 71(1) (2015)

7. A. Hadavi, H. Kermanshahi, H. Nassiri Moghaddam, A. Golian, Effects of Fennel Extract on Egg Production, Antioxidant Status and Bone Attributes of Laying Hens Administered Carbon Tetrachloride, Poultry Science Journal, 5(2) (2017)

8. A.E. Widodo, J.V. Nolan, M. Akter, H.M. O'Neill, P.A. Iji, Response of Broiler Chickens to TriticaleBased Diets Supplemented with Microbial Enzymes, Poultry Science Journal, 6(1) (2018)

9. L.I. Podobed, The effect of silicon on the bird organism, Modern poultry (Kiev), 7(140) (2014)

10. S.V. Eremin, The effect of nanobiological fodder additive "NaBiKat" in broiler chick diets on their productivity and hematological parameters, Scientific Journal of KubSAU, 121 (2016)

11. I.C. Boleli, V.S Morita, Poultry Egg Incubation: Integrating and Optimizing Production Efficiency, Brazilian Journal of Poultry Science, Special Issue 2 Incubation, 1-16 (2016) 